\title{
Management of overactive bladder syndrome
}

\author{
Sushma Srikrishna, Dudley Robinson, Linda Cardozo, Maria Vella
}

Postgrad Med J 2007;83:481-486. doi: 10.1136/pgmj.2007.057232

Overactive bladder (OAB) syndrome is the term used to describe the symptom complex of urinary urgency with or without urge incontinence, usually with frequency and nocturia. Drug treatment continues to have an important role in the management of women with $O A B$. Other treatment options include conservative management with lifestyle interventions, modification of fluid intake, and physiotherapy including bladder retraining. Surgery remains the last resort in the treatment and is usually reserved for intractable detrusor overactivity, as it is associated with significant morbidity. This article reviews the management of the overactive bladder with specific focus on newer developments in the medical treatment of $O A B$ in women.

See end of article for authors' affiliations

Correspondence to:

Dr Sushma Srikrishna,

Department of

Urogynaecology, King's

College Hospital, Denmark

Hill, London SE5 9RS, UK;

sushmasrikrishna@hotmail. com

Received 9 January 2007 Accepted 24 April 2007

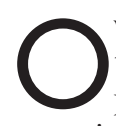
veractive bladder $(\mathrm{OAB})$ syndrome is the term used to describe the symptom complex of urinary urgency with or without urge incontinence, usually with frequency and nocturia. ${ }^{1}$ Recent epidemiological studies have reported an overall prevalence of $\mathrm{OAB}$ in women of $16.9 \%$, suggesting that there could be 17.5 million women in the USA who suffer from this condition. The prevalence increases with age, from $4.8 \%$ in women under 25 years to $30.9 \%$ in those over the age of 65 years. ${ }^{2}$ This is supported by prevalence data from Europe in which 16776 interviews were conducted in a population based survey. ${ }^{3}$

The symptoms of $\mathrm{OAB}$ are primarily due to involuntary contractions of the detrusor muscle during the filling phase of the micturition cycle. These involuntary contractions, when observed during urodynamic studies, are termed detrusor overactivity and are mediated by acetylcholineinduced stimulation of bladder muscarinic receptors. ${ }^{4}$

Drug treatment continues to have an important role in the management of women with $\mathrm{OAB}$, although many of the agents used have not been number of preparations studied it is clear that there are no ideal drugs and very often the clinical results have been disappointing, this being due to both poor efficacy and side effects. ${ }^{6}$ Comparison of drug treatments for $\mathrm{OAB}$ is hampered by a placebo effect of $30-40 \%$; since the response to any drug is only in the region of $60 \%$, any differences detected are likely to be small, thus requiring large-scale studies to demonstrate an effect. In addition, anticholinergic treatment is associated with significant side effects. A questionnaire follow up study of women with detrusor overactivity showed subjected to controlled clinical trials. ${ }^{5}$ From the that only $18.2 \%$ women continued drug treatment for more than 6 months, partly due to the side effects of anticholinergic therapy. ${ }^{7}$ The current approaches to improving the treatment of $\mathrm{OAB}$ include delayed release formulations of existing oral agents, new pharmaceutical agents with greater specificity/selectivity, and alternative routes of administration. The purpose of this article is to review the management of the overactive bladder, with specific focus on newer developments in the medical treatment of $\mathrm{OAB}$ in women.

\section{CONSERVATIVE MANAGEMENT}

A conservative approach is often justified, especially if symptoms are only mild, or easily manageable.

\section{Lifestyle interventions}

The frequency-volume chart, or urinary diary, is an important tool in the investigation of patients with lower urinary tract symptoms and voiding dysfunction. ${ }^{8}$ This facilitates history taking regarding frequency, nocturia and volume voided, and has been shown to be valuable and reliable for the assessment of micturition patterns. ${ }^{9}$ There is poor correlation between subjective estimates of diurnal and nocturnal urinary frequency and objective charted measurements. ${ }^{10}$ Moderation of fluid intake to $1-1.5$ litres per day reduces urine production and can ease symptoms. Alcohol, caffeine, and medication such as diuretics are major causes of acute incontinence, especially in the elderly. ${ }^{11}$ Drug regimens avoiding diuretics, control of chronic cough and constipation, cessation of smoking, exclusion or treatment of urinary tract infection, and weight reduction are desirable.

\section{Physiotherapy}

Behavioural therapy for detrusor overactivity was first reported by Jeffcoate and Francis who, in the 1960s, advocated the practice of voiding "by the

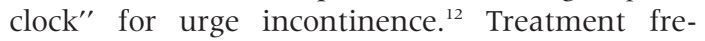
quently consists of bladder re-training by "bladder drill", to re-learn the cortical inhibition of detrusor contractions. This may be time consuming and frustrating-correct diagnosis is necessary to ensure maximum patient compliance with treatment. Behavioural modification improves central control of bladder function, avoiding the mortality and morbidity of surgery, and the side-effects of drug treatment. However, this type of treatment requires high levels of motivation and encouragement, and suffers from high relapse rates.

Studies of "bladder drill" lack consistency in their nomenclature and methodology. However, in a review of the randomised clinical trials of conservative treatments, Berghams et al ${ }^{13}$ showed 
strong evidence that bladder drill is more effective than no treatment, and weak evidence that bladder drill is better then drug treatment. There is insufficient evidence, though, of the efficacy of bladder drill with drug treatment, bladder drill with pelvic floor exercises and biofeedback, or biofeedback and behavioural therapy, due to inadequate clinical trials.

\section{DRUG TREATMENT Oxybutynin}

Oxybutynin is a tertiary amine that undergoes extensive firstpass metabolism to an active metabolite, $\mathrm{N}$-desmethyl oxybutynin, ${ }^{14}$ which occurs in high concentrations ${ }^{15}$ and is thought to be responsible for a significant part of the action of the parent drug. It has a mixed action consisting of both an antimuscarinic and a direct muscle relaxant effect, in addition to local anaesthetic properties. The latter is important when given intravesically but probably has no effect when given systemically. Oxybutynin has been shown to have a high affinity for muscarinic receptors in the bladder ${ }^{16}$ and has a higher affinity for $M_{1}$ and $M_{3}$ receptors over $M_{2} \cdot{ }^{17}$

The effectiveness of oxybutynin in the management of patients with detrusor overactivity is well documented.

\section{Extended release oxybutynin}

More recently a controlled release oxybutynin preparation using an osmotic system (OROS) has been developed which has been shown to have comparable efficacy to immediate release oxybutynin, although associated with fewer adverse effects. ${ }^{18}$ These findings are in agreement with a further study of controlled release oxybutynin (Ditopan XL, Lyrinel XL) which reported the incidence of moderate to severe dry mouth to be $23 \%$, with only $1.6 \%$ of participants discontinuing the medication due to adverse effects. ${ }^{19}$ A recent study, however, has also found that use of extended release oxybutynin in elderly subjects may impair recent memory. ${ }^{20}$

\section{Transdermal oxybutynin}

In order to maximise efficacy and minimise adverse effects, alternative delivery systems are currently under evaluation. An oxybutynin transdermal delivery system (Kentera) has recently been developed and compared with extended release tolterodine in 361 patients with mixed urinary incontinence. Both agents significantly reduced incontinence episodes, increased volume voided and led to an improvement in quality of life when compared to placebo. The most common adverse event in the oxybutynin patch arm was application site pruritis in $14 \%$, although the incidence of dry mouth was reduced to $4.1 \%$ compared to $7.3 \%$ in the tolterodine arm. ${ }^{21}$

Oxybutynin gel is also a new development currently being pursued.

\section{Propiverine}

Propiverine has been shown to combine anticholinergic and calcium channel blocking actions ${ }^{22}$ and is the most popular drug for detrusor overactivity in Germany, Austria and Japan. Open label studies in patients with detrusor overactivity have demonstrated a beneficial effect ${ }^{23}$; in a double blind placebocontrolled trial of its use in neurogenic detrusor overactivity it has been shown to increase bladder capacity and compliance significantly in comparison to placebo. Dry mouth was experienced by $37 \%$ in the treatment group as opposed to $8 \%$ in the placebo group, with dropout rates being $7 \%$ and $4.5 \%$, respectively. ${ }^{24}$

\section{Tolterodine}

Tolterodine is a competitive muscarinic receptor antagonist with relative functional selectivity for bladder muscarinic receptors ${ }^{25}$; while it shows no specificity for receptor subtypes it does appear to target the bladder over the salivary glands. ${ }^{26}$ The drug is metabolised in the liver to the 5-hydroxymethyl derivative, which is an active metabolite with a similar pharmacokinetic profile and is thought to contribute to the therapeutic effect. ${ }^{27}$

Tolterodine is also available as an extended release once daily preparation, Detrusitol XL. A recent double blind multicentre trial of 1235 women compared extended release tolterodine to immediate release tolterodine and placebo and found that the extended release preparation was found to be significantly more effective. ${ }^{28}$ In addition to increased efficacy, extended release tolterodine has been shown to have better tolerability. In a double-blind, multicentre, randomised placebo controlled trial of 1529 patients, extended release tolterodine was found to be $18 \%$ more effective in the reduction of episodes of urge incontinence while having a $23 \%$ lower incidence of dry mouth. ${ }^{29}$

Comparative randomised controlled trials such as the OPERA (Overactive bladder: Performance of Extended Release Agents), ${ }^{30}$ OBJECT (Overactive Bladder: Judging Effective Control and Treatment) ${ }^{31}$ and ACET (Antimuscarinic Clinical Effectiveness Trial) study ${ }^{32}$ have confirmed its effectiveness.

Several randomised, double-blind, placebo controlled trials, both on patients with idiopathic detrusor overactivity and neurogenic detrusor overactivity, have demonstrated a significant reduction in incontinent episodes and micturition frequency. ${ }^{33-35}$ Further studies have confirmed the safety of tolterodine, and at the recommended daily dosage the incidence of adverse events was no different to that in patients taking placebo. ${ }^{36}$

In addition, the safety and efficacy of tolterodine has also been compared to that of oxybutynin. These have suggested that although clinical efficacy is comparable for both drugs, oxybutynin was associated with higher withdrawal rates and a higher incidence of adverse events, notably dry mouth. ${ }^{37} 38$

More recently tolterodine has also been developed as an extended release once daily preparation, Detrusitol XL.

\section{Trospium}

Trospium chloride is a quaternary ammonium compound which is non-selective for muscarinic receptor subtypes, and shows low biological availability. ${ }^{39}$ It crosses the blood-brain barrier to a limited extent and hence would appear to have few cognitive effects. ${ }^{40}$ In a recent placebo-controlled, randomised, double-blind, multicentre trial trospium chloride produced significant improvements in maximum cystometric capacity and bladder volume at first involuntary contraction. Clinical improvement was significantly greater in the group receiving trospium and the frequency of adverse events was similar in both groups. ${ }^{41}$ Trospium chloride has also been compared to oxybutynin in a randomised, double-blind, multicentre trial. With both agents there was a significant increase in bladder capacity, a decrease in maximum voiding detrusor pressure, and a significant increase in compliance although there were no statistically significant differences between the two treatment groups. Those taking trospium had a lower incidence of dry mouth (4\% vs $23 \%)$ and were also less likely to withdraw $(6 \%$ vs $16 \%$ ) when compared to the group receiving oxybutynin. ${ }^{42}$

\section{Solifenacin}

Solifenacin is a potent $\mathrm{M}_{3}$ receptor antagonist that has selectivity for the $M_{3}$ receptors over $M_{2}$ receptors and has much higher potency against $M_{3}$ receptors in smooth muscle than it does against $M_{3}$ receptors in salivary glands. Despite solifenacin expressing a higher potency than darifenacin in a model of inhibition of $\mathrm{M}_{3}$ receptor mediated calcium ion mobilisation in guinea pig colonic smooth muscle cells, ${ }^{43}$ it has been shown to be 40 -fold less potent than oxybutynin and 
79-fold less potent than tolterodine in its inhibition of salivary secretion $^{44}$ as well as being more selective for the $M_{3}$ receptor.

The clinical efficacy of solifenacin has been assessed in several multicentre, randomised trials at the dose of $5 \mathrm{mg}$ and $10 \mathrm{mg}$ once daily in patients with overactive bladder. ${ }^{45-47}$

These studies suggest that solifenacin appears to be an effective treatment for $\mathrm{OAB}$, with the most commonly reported adverse events being dry mouth, constipation and blurred vision.

\section{Darifenacin}

Darifenacin is a tertiary amine with moderate lipophilicity and is a highly selective $M_{3}$ receptor antagonist, which has been found to have a fivefold higher affinity for the human $M_{3}$ receptor relative to the $M_{1}$ receptor. ${ }^{48}$ Darifenacin is equipotent with atropine in the ileum and bladder and six times less potent at inhibiting muscarinic receptors in the salivary gland. Salivary responses are inhibited at doses 6-10-fold higher than those required to inhibit bladder responses.

The efficacy of darifenacin has been investigated in multicentre studies. ${ }^{49} 50$ The most common adverse events were mildto-moderate dry mouth and constipation with a central nervous system (CNS) and cardiac safety profile. Darifenacin was significantly superior to placebo for improvements in micturition frequency, bladder capacity, frequency of urgency, severity of urgency, and number of incontinence episodes leading to a change in clothing or pads. However, there was no significant reduction in nocturia.

Darifenacin has been launched in Europe and North America, and has just been licensed for use in the UK. Since it is the most $M_{3}$ specific of the newer anti-muscarinic agents, may offer a better balance between efficacy and unwanted effects.

\section{Botulinum toxin (Botox)}

There are seven immunologically distinct antigenic subtypes of botulinum toxin, of which type A is the most widely used. Botulinum toxin A (Botox) is a purified neurotoxin complex, which blocks the release of acetylcholine and other transmitters from presynaptic nerve endings. This results in decreased muscle contractility and muscle atrophy at the injection site. The produced chemical denervation is reversible as axons are regenerated in about 3-6 months. Botox cannot cross the blood-brain barrier and hence has no CNS side effects.

The minimal invasiveness of Botox-A toxin injection in the bladder makes it attractive in the treatment of refractory detrusor overactivity. Studies have shown success rates between $26-80 \% .^{51-53}$ Data are lacking on dose, concentration, site, and number of injection and long term efficacy and side effects. A recent prospective, non-randomised, ongoing study has evaluated the efficacy and safety of botulinum-A toxin injections in the detrusor muscle to treat patients with idiopathic overactive bladder resistant to conventional treatment. ${ }^{54}$ Eighty-eight per cent of the patients showed significant improvement in bladder function in regard to subjective symptoms, quality of life and urodynamic parameters $(p<0.001)$. Urgency disappeared in $82 \%$ of the patients and incontinence resolved in $86 \%$ within $1-2$ weeks after botulinum-A toxin injections. There were no severe side effects except temporary urine retention in four cases. Mean (SD) efficacy of duration was 6 (2) months.

\section{Calcium channel blocking agents}

Contractile activity in bladder smooth muscle is activated by the movement of extracellular calcium into the cell. Spontaneous and evoked contractile activity is mediated by membrane depolarisation and the movement of calcium into the smooth muscle cell through L-type $\mathrm{Ca}^{2+}$ channels. ${ }^{55}$ The inhibition of the entrance of extracellular calcium with L-type $\mathrm{Ca}^{2+}$ blocking agents, such as nifedipine, can prevent spontaneous and evoked contractile activity. ${ }^{56}$

Nifedipine has been shown to reduce the frequency and amplitude of detrusor contractions, ${ }^{57}$ although these findings were not confirmed in a further study which found there was no significant effect on detrusor contractions. ${ }^{58}$ Similar contradictory findings have been reported regarding the use of flunarizine. ${ }^{69}$ Diltiazem has also been shown to significantly increase bladder capacity, lower bladder pressure and decrease the number of episodes of incontinence. ${ }^{60}$

At present there is insufficient evidence to suggest that calcium channel blocking agents are effective in the treatment of detrusor overactivity, although the development of a selective calcium channel blocking agent which eliminates spontaneous contractions without affecting micturition may prove to be of use in the treatment of detrusor overactivity.

\section{Other}

Imipramine and other tricyclic antidepressants have been shown to have systemic anticholinergic effects ${ }^{61}$ and blocks reuptake of serotonin. Some authorities have found a significant effect in the treatment of patients with detrusor overactivity ${ }^{62}$ although others report little effect. ${ }^{63}$ Their role in detrusor overactivity remains of uncertain benefit, although they are often useful in patients complaining of nocturia and bladder pain. These must be used with caution in the elderly due to possible cardiac effects and an increase in falls.

Desmopressin (DDVAP)-synthetic vasopressin-has a potent antidiuretic effect, being used in the management of diabetes insipidus and nocturnal enuresis. More recently it has been shown to be effective in reducing nocturia in patients with both neuropathic and non-neuropathic bladders. ${ }^{64}$ Recent studies have also demonstrated benefit in daytime urinary frequency and urinary incontinence. ${ }^{65}$

Intravesical instillations of capsaicin, a neurotoxin extracted from red chilli peppers, ${ }^{66}$ have significant effect over placebo in the treatment of neurogenic detrusor overactivity. Its analogue resiniferatoxin ${ }^{67}$ has been shown to have fewer side effects, with an increase in bladder capacity. However, the place of these neurotoxins in clinical practice is still uncertain.

\section{NEW DEVELOPMENTS \\ Potassium channel opening agents}

The opening of $\mathrm{K}^{+}$ion channels in the membrane of the detrusor muscle cell results in an increase in $\mathrm{K}^{+}$movement out of the cell, resulting in membrane hyperpolarisation ${ }^{68}$ This reduces the opening probability of ion channels involved in membrane depolarisation and hence excitability is reduced. ${ }^{69}$ Three types of potassium channels have been identified in the detrusor muscle: ATP sensitive channels, calcium-dependent large conductance channels; and calcium-dependent large conductance channels. ${ }^{32}$ At present the relationship between each of these types of channels and the myogenic, neurogenic and micturition forms of detrusor contraction has not been determined. To date cromakalim, nicorandil and pinacidil have been investigated, although newer agents are currently under development. ${ }^{70}$

Potassium channel openers are thought to be active during the bladder filling phase and, while abolishing spontaneous detrusor contractions, are not thought to affect normal bladder contractions. However, their clinical usefulness is limited by significant cardiovascular effects, with cromakalim and pinacidil being found to be up to 200 times more potent as inhibitors of vascular preparations than of detrusor muscle. ${ }^{71}$ In clinical trials assessing the use of these drugs in patients with detrusor overactivity, no bladder effects have been found at doses which already lower blood pressure. ${ }^{72}$ More recently 


\section{National guidelines from NICE}

The National Institute for Health and Clinical Excellence (NICE) has recently published guidelines on the management of urinary incontinence in women. This can be downloaded from www.nice.org.uk/CG040. The guidelines for management of $O A B$ are summarised below:

- Assessment and investigation-At initial clinical assessment, incontinence should be categorised based on the patient's symptoms and treatment should be directed towards the predominant symptom. Bladder diaries should be used in the initial assessment with a minimum of 3 days of the diary. The use of urodynamics is not recommended before conservative treatment.

- Conservative management-Bladder training for a minimum of 6 weeks should be offered as first line treatment.

- Drug treatment-Immediate release non-proprietary oxybutynin should be offered as first line drug treatment if bladder training has been ineffective. If this is not well tolerated, darifenacin, solifenacin, tolterodine, trospium or an extended release or transdermal formulation of oxybutynin should be considered as alternatives. Women should be counselled about the side effects of antimuscarinic drugs.

- Surgical management-Sacral nerve stimulation is recommended for women who have detrusor overactivity not responsive to conservative or medical treatment.

- Competence of surgeons performing operative procedures for incontinence in women-Surgery for incontinence should only be undertaken by surgeons who have received appropriate training in the management of incontinence and associated disorders or who work within a multidisciplinary team with this training and who regularly carry out this form of surgery.

newer drugs with $\mathrm{K}_{\mathrm{ATP}}$ channel opening properties have been described, ${ }^{73}$ which may be useful for the treatment of bladder overactivity; however, at present, there is no evidence to suggest that $\mathrm{K}^{+}$channel openers represent a viable treatment alternative. A recent randomised double-blind study also failed to show any beneficial effect of potassium channel openers over placebo in patients with overactive bladder. ${ }^{74}$ Hence, more work is needed to establish the role of this form of therapy in OAB.

\section{$\alpha$-Adrenoceptor antagonists}

While it is well known that $\alpha$-adrenoceptor antagonists are useful in the treatment of benign prostatic hyperplasia in men, ${ }^{75}$ there are no clinical trials showing their efficacy in OAB. In addition, in women these drugs may exacerbate or result in stress incontinence. ${ }^{76}$

\section{$\beta$-Adrenoceptor agonists}

There is evidence that $\beta$-adrenoceptor agonists increase bladder capacity in man. ${ }^{77}$ In a double-blind study, clenbutorol was shown to have a good therapeutic effect in women with detrusor overactivity. ${ }^{78}$ Other studies have shown no effect in the elderly with detrusor overactivity ${ }^{79}$ or in the young with neurogenic detrusor overactivity. ${ }^{80}$

\section{Neurokinin antagonists}

Neurokinins are widely distributed neuropeptides in both the central and peripheral nervous system. Some studies have confirmed the presence of NK2 receptors in human detrusor

\section{Useful websites}

- www.continence-foundation.org.uk

- www.incontact.org

- www.promocon.co.uk

muscle. ${ }^{81} \mathrm{NK} 2$ receptors may play a role in the pathophysiology of $\mathrm{OAB}$, and NK2 receptor antagonists have been shown to reduce the frequency and amplitude in animal studies. ${ }^{82}$ Hence these neurokinin antagonists may prove to be useful in the treatment of detrusor overactivity.

\section{Surgery}

Many different surgical treatments have been tried in the management of detrusor overactivity, but few are still in regular use today. Abandoned procedures include bladder distension, vaginal denervation, bladder transection, and sacral neurectomy. Their demise was caused by an unacceptably high rate of complications and limited efficacy.

Surgical solutions for detrusor overactivity include sacral neuromodulation, detrusor myectomy, augmentation cystoplasty, or urinary diversion.

\section{Sacral neuromodulation}

Stimulation of the S3 nerve root by an implanted electrical pulse generator can provide effective relief from frequencyurgency symptoms. In a prospective randomised trial of sacral neuromodulation versus delay, incontinence episode frequency (IEF), severity, and pad use were all reduced in the active arm $(\mathrm{p}<0.0001) ; 47 \%$ were dry, and $29 \%$ reported a reduction in IEF of more than $50 \%$ at 6 months. ${ }^{83}$ Neuromodulation is, however, very expensive. Patients need expert assessment, and management-although it is not suitable for routine use, sacral neuromodulation appears to be useful for a selected minority. The stimulator is a small electrical pulse generator, approximately the same size as a cardiac pacemaker, and is commonly implanted in the upper outer quadrant of the buttock. Complications most commonly reported are generator site pain $(15.9 \%)$ and implant site pain (19.1\%). Lead migration may occur in up to $7 \%$. The surgical revision of technical failures and complications was $32.5 \%$. This may be expected to reduce in the future as the technological development of generators and implant leads progresses.

\section{Clam augmentation cystoplasty}

Augmentation cystoplasty is used to increase the size of the urinary reservoir and render the bladder less contractile. It is indicated in patients who lack adequate bladder capacity or detrusor compliance; who manifest debilitating frequencyurgency symptoms, with urge incontinence, urinary tract infections; who have failed to derive benefit from medical treatment; whose lifestyle is severely limited; or with high pressure urine storage endangering the upper renal tracts.

The operation most frequently used is the "clam" cystoplasty. In this procedure, ${ }^{84}{ }^{85}$ the bladder is bisected almost completely and a patch of gut (usually ileum) equal in length to the circumference of the bisected bladder (about $25 \mathrm{~cm}$ ) is sewn in place. This often cures the symptoms of detrusor overactivity ${ }^{86}$ by converting a high-pressure system into a low-pressure system, although inefficient voiding may result. Patients have to learn to strain to void, or may have to resort to clean intermittent self-catheterisation, sometimes permanently. In addition, mucus retention in the bladder may be a problem, but this can be partially overcome by ingestion of $200 \mathrm{ml}$ of cranberry juice each day ${ }^{87}$ in addition to intravesical mucolytics 
such as acetylcysteine. The chronic exposure of the ileal mucosa to urine may lead to malignant change. ${ }^{88}$ There is a $5 \%$ risk of adenocarcinoma arising in ureterosigmoidostomies, where colonic mucosa is exposed to $\mathrm{N}$-nitrosamines found in both urine and faeces, and a similar risk may apply to enterocystoplasty. Biopsies of the ileal segment taken from patients with "clam" cystoplasties show evidence of chronic inflammation of villous atrophy, and diarrhoea caused by disruption of the bile acid cycle is common. ${ }^{89}$ This may be treated using cholestyramine. In addition, metabolic disturbances such as hyperchoraemic acidosis, B12 deficiency and occasionally osteoporosis secondary to decreased bone mineralisation may occur.

\section{Detrusor myectomy}

Detrusor myectomy offers an alternative to clam cystoplasty by increasing functional bladder capacity without the complications of bowel interposition. In this procedure the whole thickness of the detrusor muscle is excised from the dome of the bladder, thereby creating a large bladder diverticulum with no intrinsic contractility. ${ }^{90}$ While there is a reduction in episodes of incontinence there is little improvement in functional capacity and thus frequency remains problematic. ${ }^{11} 92$

\section{Urinary diversion}

As a last resort for those women with severe detrusor overactivity or neurogenic detrusor overactivity who cannot manage clean intermittent catheterisation, it may be more appropriate to perform a urinary diversion. Usually this will utilise an ileal conduit to create an abdominal stoma for urinary diversion. An alternative is to form a continent diversion using the appendix (Mitrofanoff) or ileum (Koch pouch) which may then be drained using self-catheterisation.

\section{CONCLUSION}

Pharmacological treatment, in addition to bladder retraining, remains important in the management of women with symptoms of the $\mathrm{OAB}$ syndrome. While tolerability has previously limited compliance, the development of long acting agents with a better adverse event profile has improved this dramatically. The development of new $\mathrm{M}_{3}$ specific and bladder selective muscarinic antagonists may also improve efficacy and compliance while limiting adverse effects. Intravesical injection of Botox A toxin has a role in refractory detrusor overactivity, although there are still concerns regarding long term efficacy and side effects. The development of calcium antagonists and potassium channel opening agents may offer alternatives to anti-muscarinic treatment, although at present there are no clinically useful drugs available. The potential role of $\alpha$ adrenoreceptor antagonists, $\beta$-adrenoreceptor agonists and neurokinin antagonists remains to be elucidated. Surgery remains the last resort in management of intractable detrusor overactivity.

Ultimately, perhaps a better understanding of the causes and pathophysiology of overactive bladder syndrome may result in the development of new treatments for such a common and distressing condition.

\section{Authors' affiliations}

Sushma Srikrishna, Dudley Robinson, Linda Cardozo, Maria Vella, Department of Urogynaecology, King's College Hospital, London, UK

Competing interests: None stated

\section{REFERENCES}

1 Abrams P, Cardozo L, Fall M, et al. The standardisation of terminology of lower urinary tract function: report from the Standardisation Sub-committee of the International Continence Society. Neurourol Urodyn 2002;21:167-78.
2 Stewart WF, Corey R, Herzog AR, et al. Prevalence of overactive bladder in women: results from the NOBLE program. Int Urogynaecol J 2001;12:S66.

3 Milsom I, Abrams P, Cardozo L, et al. How widespread are the symptoms of overactive bladder and how are they managed? A population-based prevalence study. BJU Int 2001;87:760-6.

4 Andersson K-E. The overactive bladder: Pharmacologic basis of drug treatment. Urology 1997;50(6A Suppl.):74-84.

5 Andersson K-E. Current concepts in the treatment of disorders of micturition. Drugs 1988;35:477-94.

6 Kelleher CJ, Cardozo LD, Khullar V, et al. A medium-term analysis of the subjective efficency of treatment for women with detrusor instability and low bladder compliance. Br J Obstet Gynaecol 1997;104:988-93.

7 Kelleher CJ, Cardozo LD, Khullar V, et al. A medium-term analysis of the subjective efficacy of treatment for women with detrusor instability and low bladder compliance. Br J Obstet Gynaecol, 1997104, 988-93.

8 Abrams $\mathbf{P}$, Fenely R, Torrens $M$. Patient assessment. In: Abrams $P$, Fenely $R$, Torrens M, eds. Urodynamics, 1 st ed. New York: Springer, 1983:6-27.

9 Larsson G, Victor A. Micturition patterns in a healthy female population, studied with a frequency-volume chart. Scand J Urol Nephrol Suppl 1988;1 14:53-7.

10 McCormack M, Infante-Rivard C, Schick E. Agreement between clinical methods of measurment of urinary frequency and functional bladder capacity. $\mathrm{Br} J$ Urol 1992;9:17-21.

11 Linjakumpu T, Hartikainen S, Klaukka T, et al. Psychotropics among the home dwelling elderly -increasing trends. Int J Geriatr Psychiatry 2002;17:874-83.

12 Jeffcoate TN, Francis WJ. Urgency incontinence in the female. Am J Obstet Gynecol 1966;94:604-18.

13 Berghams LC, Hendriks HJ, De Bie RA, et al. Conservative treatment of urge urinary incontinence in women: a suystematic review of randomised clinical trials. BJU Int 2000;85:254-63.

14 Waldeck K, Larsson B, Andersson KE. Comparison of oxybutynin and it's active metabolite, $\mathrm{N}$-desmethyl-oxybutynin, in the human detrusor and parotid gland. $J$ Urol 1997; 157:1093-7.

15 Hughes KM, Lang JCT, Lazare R, et al. Measurement of oxybutynin and its $\mathrm{N}$ desethyl meatbolite in plasma, and its application to pharmacokinetic studies in young, elderly and frail elderly volunteers. Xenobiotica 1992;22:859-69.

16 Nilvebrant L, Andersson KE, Mattiasson A. Characterization of the muscarinic cholinoreceptors in the human detrusor. J Urol 1985;134:418-23.

17 Nilvebrant L, Sparf B. Dicyclomine, benzhexol and oxybutynin distingush between subclasses of muscarinic binding sites. Eur J Pharmacol 1986;123:133-43.

18 Anderson RU, Mobley D, Blank B, et al. Once daily controlled versus immeadiate release oxybutynin chloride for urge urinary incontinence. OROS Oxybutynin Study Group. J Urol 1999;161:1809-12.

19 Gleason DM, Susset J, White C, et al. Evaluation of a new once-daily formulation of oxybutynin for the treatment of urinary urge incontinence. Ditropan XL Study Group. Urology 1999;54:420-3.

20 Kay G, Kardiasmenos K, Crook T. Differential effects of the antimuscarinic agents toterodine tartarate ER and oxybutynin chloride ER on recent memory in older subjects. Abstract presented at the Meeting of the International Continence Society, New Zealand: Christchurch, 2006.

21 Dmochowski RR, Sand PK, Zinner NR, Transdermal Oxybutynin Study Group, et al. Comparative efficacy and safety of transdermal oxybutynin and oral tolterodine versus placebo in previously treated patients with urge and mixed urinary incontinence. Urology 2003;62:237-42.

22 Haruno A, Yamasaki Y, Miyoshi K, et al. Effects of propiverine hydrochloride and its metabolites on isolated guinea pig urinary bladder. Folia Pharmacol Japon 1989:94:145-50.

23 Mazur D, Wehnert J, Dorschner W, et al. Clinical and urodynamic effects of propiverine in patients suffering from urgency and urge incontinence. Scand JUrol Nephrol 1995;29:289-94.

24 Stoher M, Madersbacher H, Richter R, et al. Efficacy and safety of propiverine in $\mathrm{SCl}$-patients suffering from detrusor hyperreflexia: a double-blind, placebocontrolled clinical trial. Spinal Cord 1999;37:196-200.

25 Ruscin JM, Morgenstern NE. Tolterodine use for symptoms of overactive bladder. Ann Pharmacother 1999;33:1073-82.

26 Nilvebrant L, Andersson K-E, Gillberg P-G, et al. Tolterodine - a new bladder selective antimuscarinic agent. Eur J Pharmacol 1997;327:195-207.

27 Nilvebrant L, Hallen B, Larsson G. Tolterodine - a new bladder selective muscarinic receptor antagonist: preclinical pharmacological and clinical data. Life Sci 1997;60:1129-36.

28 Swift S, Garely A, Dimpfl T, Payne C, Tolterodine Study Group. A new once daily formulation of tolterodine provides superior efficacy an is well tolerated in women with overactive bladder. Int J Pelvic Floor Dysfunct 2003;14:50-4.

29 Van Kerrebroeck P, Kreder K, Jonas U, Tolterodine Study Group, et al. Tolterodine once-daily: superior efficacy and tolerability in the treatment of overactive bladder. Urology 2001;57:414-21.

30 Diokno AC, Appell RA, Sand PK, OPERA Study Group, et al. Prospective, randomised, double blind study of the efficacy and tolerability of the extendedrelease formulations of oxybutynin and tolterodine for overactive bladder: results of the OPERA trial. Mayo Clin Proc 2003;78:687-95.

31 Appell RA, Sand P, Dmochowski R, Overactive Bladder: Judging Effective Control and Treatment Study Group, et al. Prospective randomized controlled trial of extended-release oxybutynin chloride and tolterodine tartrate in the treatment of overactive bladder: results of the OBJECT Study. Mayo Clin Proc 2001;76:358-63.

32 Sussman D, Garely A. Treatment of overactive bladder with once-daily extended-release tolterodine or oxybutynin: the antimuscarinic clinical effectiveness trial (ACET). Curr Med Res Opin 2002;18:177-84.

33 Hills CJ, Winter SA, Balfour JA. Tolterodine. Drugs 1998;55:813-20. 
34 Jonas $\mathrm{U}$, Hofner K, Madesbacher $\mathrm{H}$, et al. Efficacy and safety of two doses of tolterodine versus placebo in patients with detrusor overactivity and symptoms of frequency, urge incontinence, and urgency: urodynamic evaluation. World J Urol 1997; 15:144-51.

35 Millard R, Tuttle J, Moore K, et al. Clinical efficacy and safety of tolterodine compared to placebo in detrusor overactivity. J Urol 1999:161:1551-5.

36 Rentzhog L, Stanton SL, Cardozo LD, et al. Efficacy and safety of tolterodine in patients with detrusor instability: a dose ranging study. Br J Urol 1998;81:42-8.

37 Abrams $\mathbf{P}$, Freeman $\mathrm{R}$, Anderstrom $\mathrm{C}$, et al. Tolterodine, a new antimuscarinic agent: as effective but better tolerated than oxybutynin in patients with an overactive bladder. Br J Urol 1998;81:801-10.

38 Appell RA. Clinical efficacy and safety of tolterodine in the treatment of overactive bladder: a pooled analysis. Urology 1997;50:90-6.

39 Schladitz-Keil G, Spahn H, Mutschler E. Determination of bioavailability of the quaternary ammonium compound trospium chloride in man from urinary excretion data. Arzneimittel Forsch/Drug Res 1986;36:984-7.

40 Fusgen I, Hauri D. Trospium chloride: an effective option for medical treatment of bladder overactivity. Int J Clin Pharmacol Ther 2000;38:223-34.

41 Cardozo LD, Chapple CR, Toozs-Hobson P, et al. Efficacy of trospium chloride in patients with detrusor instability: a placebo-controlled, randomized, doubleblind, multicentre clinical trial. BJU Int 2000;85:659-64.

42 Madersbacher $\mathrm{H}$, Stoher M, Richter R, et al. Trospium choride versus oxybutynin: a randomized, double-blind, multicentre trial in the treatment of detrusor hyperreflexia. Br J Urol 1995:75:452-6.

43 Ikeda K, Kobayashi S. Effects of YM905, oxybutynin and darifenacin on carbachol induced intracellular calcium mobilization by dispersed longitudinal smooth muscle cells of guinea pig colon. Yamanouchi Pharmaceutical Co. Ltd. (1998). Registration No. D199803320-02.00. International Study ID, 905-PH 006.

44 Ikeda K, Kobayashi S. Effects of YM905, tolterodine and oxybutynin on M3 receptor mediated cytosolic free $\mathrm{Ca}^{2+}$ mobilization in acutely dissociated cells of guinea pig urinary bladder smooth muscle and murine submandibular gland. Yamanouchi Pharmaceutical Co. Ltd. (1998). Registration No. D19980321702.000, International Study ID, 905-PH-005.

45 Cardozo L, Lisec M, Millard R, et al. Randomised, double blind placebo controlled trial of the once daily antimuscarinic agent solifenacin succinate in patients with overactive bladder. J Urol 2004:172:1919-24.

46 Chapple CR, Arano P, Bosch JL, et al. Solifenacin appears effective and well tolerated in patients with symptomatic idiopathic detrusor overactivity in a placebo and tolterodine controlled phase II dose-finding study. BJU Int 2004:93:71-7.

47 Chapple CR, Martinez-Garcia R, Selvaggi L, for the STAR Study Group, et al. A comparison of the efficacy and tolerability of solifenacin succinate and extended release tolterodine at treating overactive bladder syndrome: results of the STAR trial. Eur Urol 2005:48:464-70.

48 Alabaster VA. Discovery and development of selective $M 3$ antagonists for clinical use. Life Sci 1997;60:1053-60.

49 Haab F, Stewart L, Dwyer P. Darifenacin, an M3 selective receptor antagonist, is an effective and well-tolerated once-daily treatment for overactive bladder. Eur Urol 2004;45:420-9.

50 Chapple CR. Darifenacin is well tolerated and provides significant improvement in the symptoms of overactive bladder: a pooled analysis of phase III studies. J Urol. 2004;171: 130 [abstract 487], (Suppl).

51 Rapp DE, Lucioni A, Katz EE, et al. Use of botulinum toxin A for the treatment of refractory overactive bladder symtptoms: an initial experience. Urology 2004:63:1071-5.

52 Kuo HC. Urodynamic evidence of effectiveness of botulinum A toxin injection in the treatment of detrusor overactivity refractory to anticholinergic agents. Urology 2004:63:868-72.

53 Chancellor MB, O'Leary M, Erickson J. Successful use of bladder botulinum toxin injection to treat refractory overactive bladder. J Urol 2003;169(suppl):351.

54 Schmid DM, Savermann P, Werner M, et al. Experience with 100 cases treated with botulinum-A toxin injections in the detrusor muscle for idiopathic overactive bladder syndrome refractory to anticholinergics. J Urol 2006;176:177-85.

55 Brading AF. A myogenic basis for the overactive bladder. Urol 1997;50:57.

56 Levin RM, Kitada S, Hayes L, et al. Experimental hyperreflexia: Effect of intravesical administration of various agents. Pharmacology 1991;42:54.

57 Rud T, Andersson K-E, Ulmsten U. Effects of nifedipine in women with unstable bladders. Urol Int 1979:34:421-9.

58 Laval KU, Lutzeyer W. Spontaneous phasic activity of the detrusor: a cause of uninhibited contractions in unstable bladder. Urol Int 1980;35:182-7.

59 Palmer JH, Worth PH, Exton-Smith AN. Flunarizine: a once daily therapy for urinary incontinence. Lancet 1981 ;ii:279-81.

60 Faustini S, Salvini A, Pizzi P, et al. Experimental study on the action of diltiazem on detrusor muscle and clinical evaluation in patients with detrusor hyperactivity. Arzneimittel-Forsch/Drugs Res 1989:39:899-903.
61 Stoher M, Madersbacher $H$, Richter $R$, et al. Efficacy and safety of propiverine in $\mathrm{SCl}$-patients suffering from detrusor hyper-reflexia: a double-blind, placebocontrolled clinical trial. Spinal Cord 1999:37:196-200.

62 Baldessarini KJ. Drugs in the treatment of psychiatric disorders. In: Gilman, et al, eds. The pharmacological basis of therapeutics, 7th ed.McMillan Publishing Co, 1985:387-445.

63 Castelden CM, Duffin HM, Gulati RS. Double-blind study of Imipramine and placebo for incontinence due to bladder instability. Age Aging 1986;15:229-303.

64 Diokono Ac, Hyndman CW, Hardy DA, et al. Comparison of action of imipramine (tofranil) and propantheline (probanthine) on detrusor contraction. $J$ Urol 1972;107:42-3.

65 Hilton P, Hertogs K, Stanton SL. The use of desmopressin (DDVAP) for nocturia in women multiple sclerosis. J Neurol Neurosurg Psychiatry 1983;46:854-55.

66 Robinson D, Cardozo L, Akeson M, et al. Women take control; desmopressin - a drug for daytime urinary incontinence. Neurourol Urodyn 2002;21:385-6.

67 de Seze M, Wiart L, Joseph PA, et al. Caspaicin and neurogenic detrusor hyperreflexia: a double blind placebo-controlled study in 20 patients with spinal cord lesions. Neurourol Urodyn 1998;17:513-23.

68 Andersson KE. The overactive bladder: pharmacologic basis of drug treatment. Urology 1997; 50:74.

69 Andersson KE. Clinical pharmacology of potassium channel openers. Pharmacol Toxicol 1992:70:244-5

70 Lawson K. Potassium channel openers as potential theraputic weapons in ion channel disease. Kidney Int 2000;57:838-45.

71 Edwards G. Henshaw M, Miller M, et al. Comparison of the effects of several potassium-channel openers on rat bladder and rat portal vein in vitro. Br J Pharmacol 1991;102:679-86.

72 Hedlund $\mathrm{H}$, Andersson KE, Mattiasson A. Effects of pinacidil on detrusor instability in men with outlet obstruction. J Urol 1991;146:1345-7.

73 Andersson KE, Arner A. Urinary bladder contraction and relaxation: physiology and pathophysiology. Physiol Rev 2004:84:935-86.

74 Chapple CR, Patroneva A, Raines SR. Effect of an ATP-sensitive potassium channel opener in subjects with overactive bladder: a randomized, double-blind, placebo-controlled study. Eur Urol 2006;49:879-86.

75 Andersson K-E. Alpha adrenoceptors and benign prostatic hyperplasia: basic principles for treatment with alpha adrenoceptors antagonists. World J Urol 2002;19:390

76 Dwyer PL, Teele JS. Prazosin: a neglected cause of genuine stress incontinence. Obstet Gynecol 1992;79:1 17.

77 Andersson KE. Pharmacology of lower urinary tract smooth muscles and penile erectile tissues. Pharmacol Rev 1993:45:253.

78 Grunberger A. Treatment of motor urge incontinence with clenbutorol and flavoxate hydrochloride. Br J Obstet Gynaecol 1984;91:275.

79 Castleden CM, Morgan B. The effect of beta adrenoceptor agonists on urinary incontinence in the elderly. Br J Clin Pharmacol 1980;91:275.

80 Naglo AS, Nergardh A, Boreus LO. Influence of atropine and isoprenaline on detrusor hyperactivity in children with neurogenic bladder. Scan J Urol Nephrol 1981;15:97.

81 Burcher E, Zeng XP, Strigas J. Autoradiographic localization of tachykinin and calcitonin gene related peptide receptors in adult urinary bladder. J Urol 2000;163:331-7.

82 Abdel-Gawad M, Dion B, Elhilali MM. Evidence of a peripheral role of neurokinins in detrusor hyperreflexia: a further study of selective tachykinin antagonists in chronic spinal injured rats. J Urol 2001;165:1739-44.

83 Schmidt RA, Jonas U, Oleson KA, et al. Sacral nerve stimulation for treatment of refractory urinary re incontinence. Sacral Nerve Stimulation Study Group. J Urol $1999 ; 162: 352-7$

84 Mast P, Hoebke, Wyndale JJ, et al. Experience with clam cystoplasty. A review. Paraplegia 1995;33:560-4.

85 Bramble FJ. The clam cystoplasty. Br J Urol 1990;66:337-41

86 McRae $\mathbf{P}$, Murray KH, Nurse DE, et al. Clam entero-cystoplasty in the neuropathic bladder. Br J Urol 1987;60:523-5

87 Rosenbaum TP, Shah PJR, Rose GA, et al. Cranberry juice helps the problem of mucus production in enterouroplastics. Neurourol and Urodyn 1989:8:344-5.

88 Harzmann R, Weckerman D. Problem of secondary malignancy after urinary diversion and enterocystoplasty. Scand J Urol Nephrol 1992;142(suppl):56.

89 Barrington JW, Fern Davies H, Adams RJ, et al. Bile acid dysfunction after clam enterocystoplasty. Br J Urol 1995;76:169-71.

90 Cartwright PC, Snow BW. Bladder autoaugmentation: partial detrusor excision to augment the bladder without use of bowel. J Urol 1989;142:1050-3.

91 Snow BW, Cartwright PC. Bladder autoaugmentation. Urol Clin Nth Am 1996;23:323-1.

92 Kennelly MJ, Gormley EA, McGuire EJ. Early clinical experience with adult bladder autoaugmentation. J Urol 1994;152:303-6. 